\title{
Dimensi proses citizenship pendidikan: Studi kasus di Sanggar Alam (SALAM), Nitiprayan, Yogyakarta
}

\author{
Amrih Setyo Raharjo*, Fiki Ferianto \\ Fakultas Ilmu Pendidikan, Universitas Negeri Yogyakarta \\ *Corresponding Author. e-mail: amrihsetyor@uny.ac.id
}

\begin{abstract}
Abstrak
Penelitian ini mengeksplorasi dimensi-dimensi kunci dalam membangun citizenship pendidikan. Hal ini penting untuk melengkapi theoritical framework citizenship pendidikan yang belum tersusun secara spesifik. Penelitian menggunakan metode kualitatif dengan pendekatan studi kasus. Pengumpulan data menggunakan snowballing sampling melalui wawancara, observasi, dan studi dokumen guna menangkap natural setting di Sanggar alam (Salam), Nitiprayan, Yogyakarta. Salam dipilih sebagai objek penelitian karena mengaplikasikan konsep pendidikan yang berbeda dengan versi pemerintah. Metode interpretasi dari Creswell digunakan untuk menganalisis data. Sementara, metode dari Yin (2003) diaplikasikan untuk menguji kebasahan data. Hasil penelitian menunjukan bahwa ada tiga dimensi untuk membangun citizenship pendidikan, yaitu: 1) Active citizens sebagai prasyarat. Partisipasi akan terwujud saat warga negara melakukan shifting dari beneficiaries menuju active citizens. 2) Kontekstualitas sebagai karakteristik citizenship pendidikan. Belajar akan berkesan saat melibatkan lingkungan dalam prosesnya. Hal ini sejalan dengan konsep Tri Sentra versi Ki Hadjar Dewantara dan pembelajaran eksperimental versi Paulo Freire. 3) Co-production sebagai cara mengeksekusi citizenship pendidikan. Ini merupakan pendekatan untuk menciptakan layanan publik dengan mengakomodasi berbagai pihak. Co-production percaya bahwa kerjasama berbagai pihak akan mempermudah penciptaan layanan publik yang representative. Tiga hal ini adalah rangkaian dimensi untuk membangun citizenship pendidikan.
\end{abstract}

Kata kunci: citizenship pendidikan, partisipasi, active citizens, kontekstualitas, co-production

\begin{abstract}
The Study explores key dimensions in building educational citizenship. This is important to complement the theoretical framework of citizenship education that has not been specifically structured. The Research was using qualitative methods with a case study approach. Through snowballing sampling, the data was collected by interviews, observations, and document studies to capture the natural setting in Sanggar alam (Salam), Nitiprayan, Yogyakarta. Salam was chosen as the object of research because it applied a different concept of education to the government version. To analyze the data, we used the interpretation method by Creswell while the validity was tested by Yin's Method (2003). The results show that there are three dimensions to building educational citizenship, namely: 1) Active citizens as a prerequisite. Participation will be realized when citizens shift from beneficiaries to active citizens. 2) Contextual as a characteristic of education citizenship. Learning will be more effective when considering the environmental context in which the teaching and learning activities are held. This is in line with the concept of Tri Sentra by Ki Hadjar Dewantara and experimental learning by Paulo Freire. 3) Co-production as a way of executing educational citizenship. This is an approach to create public services by accommodating various parties. Coproduction believes that the cooperation of various parties will facilitate the creation of representative public services. These three things are a series of dimensions to build education citizenship.
\end{abstract}

Keywords: education citizenship, participation, active citizenship, contextuality, co-production

This is an open-access article under the CC-BY-SA license.

How to Cite: Raharjo, A. S., \& Ferianto, F. (2020). Dimensi proses citizenship pendidikan: Studi kasus di Sanggar Alam (SALAM), Nitiprayan, Yogyakarta. FOUNDASIA, 11(1), 43-51. 


\section{PENDAHULUAN}

Citizenship pendidikan adalah konsep penting dalam kebijakan publik yang masih perlu dikembangkan. Sebagaimana kajian Denhardt \& Denhardt (2007) mengafimasi bahwa diskursus kebijakan publik menempatkan demokrasi, citizenship, dan public interest sebagai komponen utamanya. Citizenhsip adalah hak dan fungsi masyarakat sebagai warga negara untuk mengintervensi masalah publik. Konsep ini menjadi relevan karena memfasilitasi aspirasi dan kebutuhan masyarakat. Konsep citizenship adalah ranah yang perlu terus dikembangkan karena dua hal: 1) sifat kebijakan publik yang dinamis. Sebagaimana kajian Dunn (1998) yang mengafirmasi bahwa masalah publik bersifat constant flux (selalu berkembang dari sisi fenomena dan solusi; 2) Sektor kebijakan publik yang kompleks membuat citizenship belum diekplorasi secara spesifik. Secara garis besar, citizenship berbicara tentang usaha mengoptimalisaskan fungsi masyarakat sebagai warga negara. Hal itu tidak hanya mencakup akses terhadap aspek formal saja, melainkan juga mencakup aspek substansial.

Citizenship berusaha menyadarkan pentingnya fungsi warga negara. Citizenship merupakan turunan dari konsep besar New Public Service (NPS). NPS adalah sebuah kerangka teoritik dalam kebijakan publik yang relevan dengan azaz demokrasi. NPS adalah konsep luwes yang menempatkan aspirasi dan kebutuhan masyarakat sebagai acuan utama (Boyte, 2005; Bozeman, 2007; Stoker, 2006). Hal itu membuat konsep ini relevan dengan tuntutan demokrasi saat ini: akomodasi kepentingan rakyat. Keadaan ini membuat citizenship menjadi diskurus penting di negara-negara demokrasi. Ekplorasi citizenship perlu dirumuskan secara spesifik karena sektor publik yang sangat kompleks. Hal itu berkaitan dengan karakteristik berbeda dari setiap sektor publik yang juga membutuhkan treatment berbeda.

Usaha merumuskan dimensi-dimensi citizenship menjadi krusial. Analoginya seperti ini, jika masalah publik adalah hama yang menggangu tanaman untuk berbuah lebat di pekarangan warga, citizenship adalah seperangkat teknologi untuk mengantisipasinya. Sementara itu, tidak ada panduan pemanfaatan teknologi-teknologi tersebut secara jelas. Sehingga antisipasi hanya muncul secara organic, tanpa dukungan pengetahuan yang memadai. Sementara, setiap tanaman memiliki karakter dan hama pengganggunya masing-masing. Oleh karena itu, butuh treatment berbeda untuk mengatasinya. Hal tersebut menjadi masalah dari optimalisasi citizenship. Akses dan hak warga tidak mampu dimanfaatkan dengan baik karena lack of knowledge. Tulisan ini berusaha menguraikan dimensi-dimensi proses dalam membangun citizenship, agar setiap masyarakat dapat memanfaatkan hak dan aksesnya secara optimal.

Pendidikan adalah sektor penting di ranah publik yang belum dielaborasi secara rinci dalam kerangka citizenship. Sektor ini menjadi penting karena kemampuannya untuk meningkatkan kesejahteraan rakyat. Kajian Piccoli (2015) menegaskan Education is a powerful mechanism for promoting and a driving force for social mobilization and enhancing public participation". Hal itu menandakan bahwa pendidikan memberikan efek yang berkelanjutan. Pendidikan berfungsi untuk meningkatkan keterampilan individu yang berguna bagi kemandirian diri. Kajian Aini et al (2018) mengafirmasi bahwa pendidikan adalah tools utama untuk mengakses kesejahteraan yang lebih baik. Oleh karena itu, penyelenggaran pendidikan yang berkualitas dan merata perlu didorong seoptimal mungkin untuk menstimulus agregat kesejahteraan yang lebih tinggi. Citizenship pendidikan perlu diaktualisasikan guna mengoptimalkan penyelenggaraan pendidikan.

Citizenship pendidikan menjadi agenda urgent karena reduksi publicness di sektor pendidikan. Hal ini mengarah pada rendahnya kualitas kebijakan pendidikan yang diselenggarakan oleh pemerintah. Penyelenggaraan pendidikan pemerintah di beberapa titik terlihat tidak mengakomodasi keadilan. Fenomena ini tercermin dari kebijakan zonasi yang belum represtatif untuk semua. Kajian Research on Improving System of Education (RISE) (2019) tentang zonasi di Yogyakarta mengafirmasi bahwa model zonasi memungkinkan murid tidak mendapat sekolah lanjutan karena tidak memenuhi syarat. Ketidakadilan lainnya terjadi pada standarisasi pendidikan yang merangsang murid sekolah hanya untuk mencari nilai dan ijasah semata. Sekolah hanya untuk mampu menjawab soal ujian nasional dan medapat ijasah dengan nilai yang baik. Fenomena ini diartikan Tilaar (2009) sebagai penyakit (diseases) dalam praktek pendidikan. Misleading praktek pendidikan menstimulus mistrust (ketidakpercayaann) terhadap pemerintah. Mal Praktek pendidikan 
tersebut perlu direspon oleh masyarakat dengan cara yang strategis. Citizenship mampu mewadai dinamika tersebut dengan memanfaatkan fungsi warga negara. Tetapi, tidak semua kekecewaan mampu ditransformasikan menjadi sebuah advokasi pendidikan yang tepat. Oleh karena itu, theoretical framework citizenship perlu segera dirumuskan sebagai referensi melakukan partisipasi pendidikan.

Kajian ini memilih Sanggar Alam (SALAM) Nitiprayan Bantul sebagai objek penelitian. Salam merupakan wujud citizenship pendidikan yang berhasil. Salam adalah sekolah non-formal dengan format pusat kegiatan belajar masyarakat (PKBM). Sekolah ini merumuskan kurikulum dengan prinsip pembelajarannya sendiri. Salam merasa pendidikan versi pemerintah tidak sesuai dengan esensi pendidikan. Sistem pendidikan pemerintah tidak mampu mengakomodasi anak menjadi mandiri sesuai dengan potensi masing-masing. Sebagimana pernyataan dari Wahyaningsih selaku Pendiri Salam Bahwa,"Pendidikan formal mencabut anak dari akaranya. karena tidak kontektual dan tidak memberi ruang agar karakter anak dapat berkembang". Salam terus berkembang sejak berdiri di tahun 2004. Saat ini Salam telah membuka jenjang pendidikan mulai dari Pendidikan Usia Dini (PAUD), Sekolah Dasar (SD), Sekolah Menengah Pertama (SMP), dan Sekolah Menengah Atas (SMA). Salam adalah komunitas organik yang tumbuh di tengah keresahan masyarakat terhadap praktek pendidikan pemerintah. Salam dapat dipotret sebagai sebuah citizenship pendidikan yang terus tumbuh. Kajian ini akan menguraikan secara spesifik dimensi-dimensi proses Salam dalam membangun citizenshipnya.

\section{METODE PENELITIAN}

Penelitian ini menggunakan metode kualitatif dengan pendekatan studi kasus dimana kasus yang coba dieksplorasi adalah citizenship Sanggar Alam (Salam) Nitiprayan, Bantul. Agar lebih fokus pada isu yang diangkat, metode dilengkapi dengan Strategi eksplanatoris sehingga dapat menguraikan rangkaian fenomena tertentu secara lengkap dan terperinci. Pendekatan ini dirasa tepat untuk mendeskripsikan fenomena yang terjadi di lokasi penelitian termasuk untuk mengetahui latarbelakang mengapa dan bagaimana fenomena itu terjadi.

Pengumpulan data menggunakan snowballing sampling. Metode ini dipilih untuk menangkap natural setting dari aktivitas di lokasi penelitian. Peneliti melakukan wawancara kepada informan secara langsung (face to face) dengan tidak terstruktur. Pertanyaan terbuka juga diberikan untuk melengkapi kemungkinan informasi lainnya. Selanjutnya, untuk melakukan validasi data peneliti menggunakan metode observasi participant serta studi dokumen sehingga data yang diperoleh lebih akurat.

Tahapan selanjutnya adalah melakukan analisis data. Pada tahap ini, Peneliti mengintepretasi dan mengelaborasi setiap informasi untuk membentuk pola-pola sebelum pada akhirnya disimpulkan. Metode ini merujuk pada Creswell (2013), Rosman dan Rillis (1998) yang dimulai dengan Raw Data, Organizing and preparing data, Reading Through All Data, Coding the data, interrelating themes/description, interpreting the meaning of themes.

\section{HASIL DAN PEMBAHASAN}

\section{Sejarah Perjalanan Salam}

Sri Wahyaningsih adalah pendiri Sanggar Alam (Salam) yang mendapat inspirasi dari Romo Mangunwijaya. Hal itu berawal saat Wahyaningsih membantu gerakan pemberdayaan Romo Mangunwijaya di Kali Code Yogyakarta pada tahun 1983-1986. Rahardjo (2015) menyebut gerakan tersebut sebagai advokasi rakyat pinggir kali. Hal itu dilakukan karena masyarakat kali Code mendapat pengabaian dari pemerintah saat itu. Berbagai pendampingan mulai dari menata rumah warga code, membuatkan Kartu Tanda Pendudukk (KTP), pendamping ekonomi, nikah massal hingga pendidikan untuk anak. Pemberdayaan Romo mangunwijaya membuahkan hasil, kawasan kumuh kali code mulai tertata rapi dari segi bangunan ataupun kehidupan. Penghargaan arsitektur internasional Aga Khan IV untuk pengembangan lingkungan, serta The Ruth and Ralph Erskine Fellowship Award untuk kategori arsitektur rakyat miskin dianugerahkan pada Beliau pada tahun 
1992 (Puspitasari \& Sutioko, 2013). Berkat pemberdayaan tersebut warga Kali Code tidak hanya mempunyai rumah yang tertata rapi, tetapi juga kesadaran pendidikan, bahkan menjadi tempat ikonik di Yogyakarta. Signifikasi dampak tersebut menginsipirasi Wahyaningsih untuk melanjutkan advokasi rakyat miskin pada ketidakadilan akses dan sistem pengelolaan negara.

Tiga tahun membantu Romo Mangunwijaya di Kali Code menumbuhkan kepekaan pada ketidakadilan dan kesenjangan yang terjadi di masyarakat. lebih dari itu, Wahyaningsih juga mendapat pembelajaran bagaimana menyalurkan critical thinking terhadap masalah, kemudian mengonverinya menjadi aksi nyata. Akhirnya, Wahyaningsih mulai merintis aksi pemberdayaannya sendiri di Lawen, banjarnegara, Jawa Tengah. Itu adalah desa tempat tinggal mertuanya. Lawen di sekitar tahun 1988 jauh dari ideal. Banyak terjadi pernikahan dini, putus sekolah dan buta huruf (Wawancara dengan Sri Wahyaningsih, 2017). Angka putus sekolah tinggi karena sekolah dianggap tidak penting. sekolah tidak ada gunanya. Kemudian, Wahyaningsih menemukan jawaban, bahwa mindset seperti itu muncul karena tidak ada kontektualitas pendidikan dan realita. Pendidikan berdiri di menara gading yang sama sekali tidak memperhatikan fenomena dan keadaan yang terjadi di sekitar. Hal itu membuat pendidikan terasa jauh dan tidak aplikatif bagi masyarakat. Masalah ini menjadi pemantik bagi Wahyaningsih untuk merintis pemberdayaan di Lawen.

Pengalaman memberdayakan masyarakat di Lawen menjadi semangat Wahyaningsih untuk mendirikan hal serupa di Nitiprayan, Yogyakarta. Tetapi, hal itu juga didasari dengan motif yang kuat. Wahyaningsih harus pindah ke Yogyakrta karena mengikuti dinas kerja Suami. Keperihatinan Wahyaningsih pada pendidikan yang tidak kontekstual dengan lingkungan. Sekolah menutup diri dari lingkungan, tidak bisa membaur dengan masyarakat, pembelajaran hanya sebatas teori-teori teksbook yang akan mejauhkan anak dengan daerah dimana mereka tinggal (Rahardjo, 2015). Hal itu membuat lingkungan sekitar semakin ditinggalkan oleh para pemuda. Lingkungan di desa dianggap sudah kuno. Pendidikan akhirnya menggiring mindset bahwa sekolah untuk menjadi buruh di kota. Fenomena tersebut membuat anak tercerabut dari akarnya (Wawancara dengan Sri Wahyaningsih, 2017). Fakta-fakta tersebut menguatkan Wahyaningsih untuk merintis permebdayaan berbasis pendidikan pada tahun 2000 di Nitiprayan, Bantul.

Salam memulai pemberdayaanya dengan sangat natural. Hal itu ditandai dengan menggerakkan para remaja untuk melakukan berbagai hal positif seperti membuat Koran desa. Prinsipnya, sebuah movement berdasar kegembiraan dan minat. Berbagai kegiatan-kegiatan diawal berdirinya Salam seperti (Salamyogyakarta.com, 2020): (1) kegiatan Seni dan Budaya berupa kegiatan teater, musik dan tari, (2) pelatihan pertanian dengan system pertanian berkelanjutan, pelatihan pendidikan anak usia dini dan pendidikan lingkungan, (3) program Lingkungan Hidup: kompos, beternak, daur ulang kertas, dan briket arang, (4) perpustakaan anak \& jurnalistik Anak, melalui Koran Ngestiharjo.

Pemberdayaan Salam terus berkembang. Taman bermain anak yang awalnya hanya terbatas untuk warga RT 004 saja, kemudian meluas untuk seluruh kampung Nitiprayan. Selanjutnya, kiprah Salam terus meluas hingga anak-anak luar desa mulai ikut bermain dan belajar. Animo yang semakin tinggi membuat Wahyaningsih membuat kelompok belajar (KB) di tahun 2004. Masyarakat menyukai cara belajar taman bermain inisiasi wahyaningsih, karena pengaplikasian prinsip belajar dan bermain. Selain itu, KB Salam juga tidak mematok biaya di awal berdirinnya. Sejak tahun 2004, Wahyaningsih mulai menggunakan nama Salam secara resmi sebagai identitas komunitas pendidikan.

Salam mulai merekrut tenaga pengajar untuk membantu pembelajaran. Kelas yang diakomodir saat itu adalah kelas usia 2-4 tahun. Bagi Salam, pendidikan anak usia dini adalah fokus untuk mengembangkan karakter. Oleh karena itu, Salam Fokus pada pengembangan adab anak sembari belajar hal-hal akademik lain. Cara belajar Salam tersebut disukai oleh wali murid. Alhasil, Salam didesak para wali murid untuk terus membuka kelas lanjutan. Dua tahun KB berjalan menghantarkan anak-anak menuju usia jenjang Taman Kanak-kanak (TK) yaitu 4-6 tahun.

Salam terus tumbuh dan membuka Jenjang demi jenjang. Kecocokan cara belajar tersebut mendorong wali murid meminta untuk melanjutkan ke tingkat SD. Pihak Salam setuju untuk membuka jenjang berikutnya karena untuk memperluas pengaruh. Hal itu akan memfasilitasi Prinsip belajar merdeka yang Salam perjuangkan. Kelas 1 SD angkatan pertama Salam kurang lebih mempunyai murid 13 anak di tahun 2008. Relawan mulai berdatangan dan berkomitmen untuk 
menjadi fasilitator tetap. Seperti Erwin Yanuaris (2008) dan Yudhistira Aridayan (2008) yang memutuskan untuk aktif sebagai fasilitator tetap Salam hingga sekarang. Satu persatu kelas terbuka dengan konsitensi angkatan pertama untuk tetap berada di Salam. Pada akhirnya ditahun 2014 saat terbukanya SD kelas 6.

Adanya kelas 6 menyisakan kendala perijinan. Saran Dinas Pendidikan (Diknas) Bantul untuk menjadi sekolah formal diabaikan oleh Salam. Hal itu karena masalah prinsip yang bersebrangan. Salam khawatir, saat menjadi sekolah formal maka prinsip belajar merdeka akan tereduksi. Eksistensi Salam yang mulai diterima masyarakat merubah treatment Diknas Bantul terhadap Salam. Diknas Bantul mulai tidak mempermasalahkan para pendidik Salam yang tidak mempunyai gelar sarjana pendidikan. Tetapi merubah syaratnya menjadi minimal sarjana. Akhirnya di tahun 2014 Salam berhasil mendapatkan ijin dengan status non-formal berfomat Pusat Kegiatan Belajar Masyarakat (PKBM). Perluasan jenjang Salam terus berlanjut hingga di tahun 2017 dibuka kelas 1 SMA yang berisi 6 anak.

\section{Pendidikan Merdeka Salam}

Gagasan Pendidikan Salam berangkat dari kritik terhadap sistem pendidikan versi pemerintah. Sitem pendidikan dianggap telah mencabut anak dari akarnya. Pendidikan telah menjauhkan anak dari lingkungan tempat mereka berasal (Wawancara dengan Sri Wahyaningsih, 2017). Pendidikan hanya sekadar berlomba untuk mendapat ijasah dan nilai yang baik. Salam beranggapan semestinya pendidikan mampu mengembangkan bakat dan moral anak melalui pembelajaran-pembelajaran yang bisa didapat dilingkungan sekitar. Prinsip tersebut secara eksplisit ditegaskan melalui motto Salam, Yaitu: "Mendengar, saya lupa; Melihat, saya ingat; Melakukan, saya paham; Menemukan sendiri, saya kuasa", (Salamyogyakarta.com, 2020).

Belajar dari peristiwa adalah prinsip pembelajaran Salam. Salam percaya pengalaman langsung akan membuat pembelajaran menjadi berkesan. Selain itu, belajar melalui media akan menggiring anak untuk mampu memahami teori yang sedang diajarkan melalui cara masing-masing. Oleh karena itu, pembelajaran Salam dimulai dengan melakukan riset sesuai kompetensi dasar yang akan dipelajari. Salam tidak membagi pembelajaran berdasar mata pelajaran seperti sekolah pada umumnya. Riset diposisikan sebagai pintu masuk fasilitator untuk menerangkan tentang komptensi yang menjadi pokok bahasan. Kemampuan fasilitator menerjemahkan riset menjadi kompetensi dasar adalah hal yang penting dalam keberhasilan pendidikan Salam.

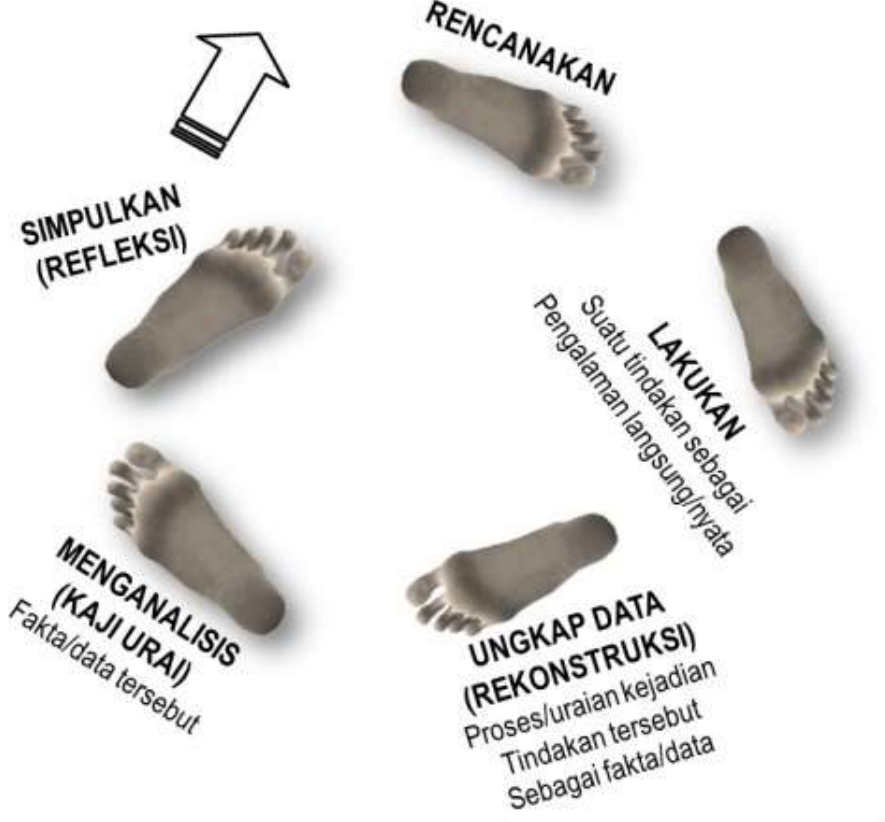

Sumber: Garis Besar Proses Belajar Sekolah Salam, 2013 
Riset kelas $1 \mathrm{SD}$ tentang riset menanam terong bisa menjadi contoh bagaimana pembelajaran Salam terjadi. Bu Erwin sebagai fasilitator kelas mengarahkan kompetensi mewarnai dan menghitung pada peristiwa melihat pertumbuhan terong. Warna-warna pada tumbuhan terong digunakan sebagai sarana mengenalkan warga ungu dan hijau. Anak akan mengalami sendiri proses memahami warna tersebut berdasar riset. Belajar di Salam menjadi menarik dan tidak melulu tentang teori yang ada di buku. Bagi Salam, Riset membuat anak lebih paham dan mengenal lingkungannya dengan baik.

\section{Diskusi: Dimensi Proses Citizenship Pendidikan}

Salam memiliki konsep pendidikannya sendiri. Kurikulum berbasis riset membuat sistem pendidikan Salam berbeda dengam model pemerintah. Kegiatan pembelajaran tidak dibagi berdasarkan mata pelajaran tetapi berdasar komptensi dasar apa yang perlu di capai pada kelas tersebut. Oleh karena itu, status kelembagaan Salam adalah sekolah Non-formal. Hal itu bertujuan agar prinsip-prinsip memerdekakan anak baik secara akademik maupun pengembangan bakat dapat terlaksana. Praktek-praktek pembelajaran tersebut adalah wujud dari citizenship ala Salam. Bagaimana Wahyaningsih mengakoordinasikan para relawan dan fasilitator untuk membangun konsep pendidikan versi mereka sendiri?

Partisipasi Pendidikan Salam terus berkembang. Hal itu terbukti dengan jenjang pendidikan yang mampu dibuka mulai dari Play Group hingga SMA. Berdasar data-data yang telah dihimpun dalam penemuan penelitian ini, maka ada dimensi-dimensi penting yang berkontribusi dalam keberhasilan citizenship Salam. Dimensi-dimensi ini penting untuk dielaborasi lebih lanjut sebagai referensi theoritical framework citizenship pendidikan. Hal ini urgent karena diskursus citizenship pendidikan belum secara detail menjelaskan tahapan dalam membangun citizenship pendidikan. Fase-fase pembangunan citizenship pendidikan di Salam adalah sebagai berikut:

\section{Active Citizens}

Keberhasilan citizenship Salam berangkat dari critical thinking dan awareness Wahyaningsih sebagai inisiator. Salam berpendapat bahwa praktek pendidikan versi pemerintah telah melenceng dari tujuannya. Tujuan pendidikan adalah untuk membimbing individu menjadi mandiri, cerdas, dan berakhlak sehingga bermanfaat masyarakat (Pasal 1 UU No 20 tahun 2003). Salam merasa pendidikan saat ini sangat bersifat industri sentris. Murid diproyeksikan sebagai buruhburuh semata tanpa memperhatikan kesesuaian kompetensi dengan lingkungan sekitar. Pendidikan saat ini sangat terbatas pada nilai, ijazah, seragam, ataupun teori-teori textbooks. Hal inilah yang mereduksi arti pendidikan. Kualitas pendidikan telah terdegradasi oleh praktek pendidikan itu sendiri. Fenomena ini disebut sebagai reduksi publicness. Wahyaningsih merasakan mal praktek pendidikan tersebut. Sementara, tidak ada jaminan bahwa pemerintah akan memperbaiki sistem pendidikannya. Mistrust terhadap kebijakan pemerintah memicu partisipasi Wahyaningsih dalam membuat konsep pendidikan versi mereka sendiri.

Citizenship menyediakan ruang -ruang partisipasi untuk warga negaranya. Hal itu karena citizenship tidak hanya berarti akses pada legal formal saja yang meliputi hak (right) dan kewajiban (Delanty, 1997). Lebih dari itu, warga negara bisa memanfaatkan ruang citizenship lain yaitu partisipasi. Partisipasi menstimulus warga negara untuk melakukan shifting dari penerima manfaat (beneficiaries) menuju active citizens.

New public service (NPS) secara teoritik mendukung pergeseran posisi peran warga negara. Hal ini karena NPS di era demokrasi sangat menghargai posisi warga negara sebagai constituent primernya. Dukungan NPS dalam kerangka citizenship harus terus dikampanyekan agar menjadi kesadaran kolektif, bahwa partisipasi adalah hak. Partisipasi harus terus diaktifkan untuk menjaga keseimbangan pengelolaan negara.

Kasus Salam menggarisbawahi pentingnya kesadaran untuk berpartisipasi. Wahyaningsih bergerak minghimpun warga, melakukan pendampingan pada remaja desa, hingga mengembangkan Salam adalah bentuk partisipasi pendidikan. Salam adalah bukti bahwa starter kick citizenship pendidikan adalah kesadaran untuk bergeser dari beneficiaries menuju active citizens. Active citizens adalah prasyarat mengagendakan citizenship pendidikan. 


\section{Kontekstualitas}

Lesson learnt selanjutnya dari citizenship pendidikan Salam adalah kontekstualitas. Aspek ini merupakan salah satu karakteristik citizenship pendidikan di Salam. Sebagaimana setiap sektor dalam kebijakan publik akan memiliki karaktertistik masing-masing. Kontekstualitas berarti pendidikan tidak bisa dilepaskan dari peran lingkungan. Pembelajaran tidak bisa melulu tentang teori-teori di buku. Salam percaya bahwa pemahaman perlu dibangun melalui pengalaman langsung. Hal itu akan memberikan kesan yang kuat dalam ingatan dan memberikan kebebasan murid untuk menguasai pengetahuan berdasar cara mereka masing-masing. Prinsip ini dituangkan dalam motto Salam, Yaitu: "Mendengar, saya lupa; Melihat, saya ingat; Melakukan, saya paham; Menemukan sendiri, saya kuasai". Tidak hanya itu, pelibatan lingkungan dalam pembelajaran penting untuk menjamin kelestarian potensi lokal, karena murid sejatinya adalah agen pelestari itu sendiri. Bukan malah dijejali dengan buku terus menerus yang tidak ada kaitannya dengan konteks dimana mereka tinggal.

Secara teoritik, beberapa tokoh pendidikan juga mendukung praktek pembelajaran langsung dan integratif versi Salam. Konsep Tri sentra ala Ki Hadjar Dewantara (KHD) adalah lokomotif paradigma ini. KHD melalui tri sentra percaya bahwa pembelajaran hanya akan berhasil saat ada integrasi antara keluarga, sekolah, masyarakat atau lingkungan (Hakim, 2016). Oleh karena itu, lingkungan dan masyarakat perlu selalu dilibatkan, baik untuk menciptakan kondisi yang suportif atau sebagai media pembelajaran. Kajian Paulo Freire dalam bingkai liberatory education mengafirmasi praktek pendidikan langsung Salam. Kajian Freire (Reed et al, 2015) terkait ProblemPosing method menjelaskan bahwa pembelajaran akan menjadi menggairahkan jika menghadirkan masalah langsung yang ada di kehidupan sekitar. Penciptaan peristiwa melalui eksperimen akan memicu kuriositas anak untuk mencari pengetahuan dan menemukan pengetahuannya sendiri.

Daur belajar Salam melalui riset adalah representasi dari prinsip kontektualitas. Kompetensi dasar dicapai melalui riset sesuai minat. Fasilitator bertugas merasionalisasikan riset dengan pokok pembahasan. Riset adalah cara paling tepat untuk menstranfer pengetahuan tanpa menggurui atau anak dapat menemukan pengtahuannya senidiri", (Wawancara dengan Fasilitator kelas 5 SD, Tri Wahyuningsih, 2017). Model ini membuat pembelajaran menjadi berkesan. Prinsip kemerdekaan belajar ini diterima dengan baik oleh wali murid. Dorongan untuk terus dibuka jenjang kelas hingga SMA adalah bukti bahwa Model pembelajaran Salam diterima.

\section{Co-Production}

Salam menyadari bahwa prinsip pendidikannya tidak dapat dibangun oleh mereka sendiri. Pendidikan merdeka Salam membutuhkan kontribusi dari berbagai pihak agar menjadi relevan. Selain itu, aplikasi pendidikan kontekstual setidaknya perlu keterlibatan lingkungan dan masyarakat. Praktek pendidikan Salam melibatkan beberapa aktor mulai dari pihak swasta, pelaku Usaha Kecil Menengah (UKM), keluarga, masyarakat, dan lingkungan. Salam tidak hanya sebagai wahana mengembangkan pendidikan, tetapi juga kendaraan menguatkan ekonomi rakyat (Wawancara dengan Sri Wahyaningsih, 2017). Salam menyebut partner kerjasamanya sebagai "kerabat Salam". Pada prakteknya Salam benar-benar mengaplikasikan prinsip tri sentra dari Ki Hadjar Dewantara.

Secara teoritik, pratek citizenship Pendidikan Salam masuk pada ranah co-production. Konsep ini mengacu pada penciptaan layanan publik dengan melibatkanberbagai macam pihak mulai dari elemen swasta, pemerintah, kalangan professional, dan bahkan pelaku bisnis (Pestoff, 2006). Bagi masyarakat, konsep ini adalah kelanjutan status dari tahap active citizens. Co-production adalah sebuah pratisipasi bersama, bahkan dari berbagai elemen tidak terkecuali pemerintah untuk membuat sebuah layanan publik yang representatif. Kajian Pestoff (2006) dan Vanleene (2019) mengafirmasi bahwa motif co-production adalah untuk mengupayakan layanan dengan public value yang cocok dengan kebutuhan. Sebuah layanan publik yang dapat menjawab keresahan masyararakat.

Salam adalah bentuk co-production dengan berbagai pihak yang terlibat. Pada prateknya, Salam bekerjasama dengan Tanoto Fondation membuat buku untuk menyebarkan konsep-konsep pendidikan merdeka. Selain itu, Salam juga bekerjasama dengan wali murid untuk membuka program ektra kulikuler sesuai minat, mengingat wali murid Salam mempunyai background profesi yang sangat variatif. UKM juga salah satu pihak yang digandeng Salam untuk mendorong dan 
melestarikan produk lokal. Selanjutnya, Pemerintah juga menjadi partner kerjasama Salam dalam menyediakan sekolah sebagai layanan publik. Walapun Salam tidak setuju dengan sistem pendidikan pemerintah, tetapi Salam tetap melakukan langkah incremental (tahap demi tahap) agar mampu menciptakan manfaat terbaik untuk murid, tanpa kehilangan prinsip pendidikan merdeka sebagai episentrum pendidikannya.

Tiga elemen tersebut adalah dimensi proses citizenship pendidikan di Salam. Elemenelemen tersebut merupakan kunci bagaimana Salam dapat terus berkembang di tengah segala keterbatasan. Active citizens, kontekstualitas, dan co-production adalah elemen-elemen yang dapat diduplikasi bagi masyarakat yang akan menginiasi sebuah citizenship pendidikan. tetapi elemen tersebut harus disesuaikan dengan keadaan sekitar agar dapat relevan.

\section{SIMPULAN \\ Pendidikan Merdeka Salam}

Salam berhasil mengembangkan citizenship pendidikannya dengan prinsip pembelajaran merdeka. Movement ini adalah bentuk aksi masyarakat Nitiprayan untuk merepson public affair yang terjadi pada sektor pendidikan. Wahyaningsih selalu inisiator Salam berpendapat bahwa sistem pendidikan versi pemerintah telah mencabut anak dari akarnya. Praktek pendidikan telah melenceng dari tujuannya. Pendidikan tidak lagi sebagai sarana untuk mengambangkan potensi diri agar dapat mandiri dan bermanfaat bagi masyarakat. Tetapi bergeser menjadi sarana agar mampu mengerjakan soal secepat mungkin untuk mencari nilai dan ijazah semata. Praktek Pendidikan versi pemerintah tidak memerdekakan murid sebagai individu yang berbeda-beda. Salam berdiri sebagai narasi alternatif untuk resepon reduksi pendidik tersebut.

Ruh konsep pendidikan Salam adalah belajar melalui peristiwa. Hal itu diwujudkan dalam pembelajaran berdasar riset. Kurikulum Salam tidak menglasifikasikan pembelajaran berdasarkan mata kuliah, tetapi melalui riset kelas ataupun individu. Selanjutnya fasilitator kelas mengarahkan riset tersebut sesuai dengan kompetensi dasar. Belajar berdasar pengalaman langsung melalui riset sesuai minat adalah bentuk pendidikan merdeka versi Salam. Partisipasi pendidikan Salam mendapat dukungan baik dari masyarakat. Hal ini ditandai dengan jenjang demi jenjang yang terus dibuka karena dorongan dari wali murid untuk tetap sekolah di Salam. Saat ini, Salam telah memiliki jenjang dari Play Group, TK, SD, SMP, hingga SMA.

\section{Dimensi Proses citizenship pendidikan}

Setiap sektor publik akan memiliki karakter sendiri dalam mengembangkan citizenshipnya. Perbedaan itu karena setiap sektor publik memiliki tujuan dan treatment masing-masing. Oleh karena itu, keberhasilan Salam mengembangkan citizenship pendidikannya sejak tahun 2004 memiliki dimensi-dimensi kunci, yaitu:

a. Active citizens

Dimensi ini adalah prasyarat citizenship pendidikan dapat terwujud. Active citizens merupakan keadaan dimana mayarakat atau komunitas menyadari masalah publik yang sedang terjadi. Citizenship tidak hanya menyediakan akses pada legal formal saja berupa hak dan kewajiban, melainkan akses pada partisipasi warga (Delanty, 1997). Partisipasi menstimulus warga negara untuk melakukan shifting dari penerima manfaat (beneficiaries) menuju active citizens. Warga negara mampu dan berhak untuk mengintervensi sektor publik yang dianggap lemah performanya. Praktek pendidikan Salam adalah contoh konkret bentuk active citizens. Wahyaningsih dan komunitas di Nitiprayan membentukan sekolah Salam dengan sistem pendidikan versi mereka. Salam adalah contoh sempurna dari warga negara yang menolak hanya sebagai beneficiaries tetapi juga sebagai active citizens. Salam memberikan alternatif sistem pendidikan lain kepada publik. Oleh karena itu, active citizens adalah dimensi awal untuk membangun citizenship pendidikan.

b. Kontekstualitas

Dimensi merupakan karakter dari citizenship pendidikan. Pelibatan lingkungan dalam pembelajaran adalah aspek penting untuk membuat pendidikan relevan dengan lingkungan. Sebagaimana kajian Freire (Reed et al, 2015) mengafirmasi bahwa pembelajaran langung melalui lingkungan akan memberikan kesan dan pemahaman yang baik pada murid. Lingkungan juga penting dalam keberhasilan pendidikan membimbing insan yang seimbang antara akademik dan moral. 
Kajian Ki Hadjar Dewantara menegasakan bahwa pendidikan akan berhasil jika mengintegrasikan antara keluarga, lingkungan, dan sekolah (Hakim, 2016). Salam berprinsip bahwa pendidikan harus kontekstual dengan lingkungan agar tidak mencerabut anak dari akarnya. Mengingat salah satu fungsi pendidikan adalah untuk menjamin kelestarian potensi lokal melalui masyarakatnya, bukan hanya tentang menhafal konsep demi konsep yang ada di buku-buku. Oleh karena itu, kontektualitas adalah dimensi penting yang perlu ada dalam membangun citizenship pendidikan.

c. Co-production

Partisipasi pendidikan perlu kontribusi dari berbagai pihak untuk menciptakan pelayanan yang relevan. Praktek pendidikan Salam melibatkan beberapa aktor mulai dari pihak swasta, pelaku Usaha Kecil Menengah (UKM), keluarga, masyarakat, dan lingkungan. Salam menyebut partner kerjasamanya sebagai "kerabat Salam". Integrasi berbagai aktor ini dapat ditangkap sebagai sebuah praktek Co-production. Konsep ini mengacu pada penciptaan layanan publik dengan melibatkanberbagai macam pihak mulai dari elemen swasta, pemerintah, kalangan professional, dan bahkan pelaku bisnis (Pestoff, 2006). Co-production adalah tahap akhir dalam mengaplikasi citizenship pendidikan.

\section{DAFTAR PUSTAKA}

Aini, E, N. Isnaini, I. Sukamti, S. (2018). Pengaruh Tingkat Pendidikan Terhadap Tingkat Kesejahteraan Masyarakat di Kelurahan Kesatrian Kota Malang. Technomedia Journal, vol. 3(1).

Boyte, H. C. (2005). Reframing Democracy: Governance, Civic Agency, and Politics. Vol. 65 (5): 536-546.

Bozeman, B. (2007). Public Values and Public Interest: Counterbalancing Economic Individualism. Georgetown University Press. Retrieved from http://www.jstor.org/stable/j.ctt2tt37c.

Creswell, J. W. (2013). Qualitative Inquiry \& Research Design: Choosing Among Five Approaches, Third Edition. Thousand Oaks, CA: Sage.

Delanty, G. (1997). Models of citizenship: Defining European identity and citizenship. Citizenship Studies, Vol. 1:3, 285-303.

Dunn, William N. (1998). Public policy analysis: An introduction (2rd ed.). Upper Saddle River, NJ: Prentice Hall.

Hakim, M, A. (2016). Meruntuhkan Budaya Kuasa dan Kekerasan pada Anak: Belajar dari Ki Hadjar Dewantara. Buana Gender, vol. 1(1).

Puspitasari, A.W. Edward Endrianto Pandelaki, E. E. Setioko, B. (2013). Pengaruh Karakteristik Karya YB. Mangunwijaya Terhadap Karakter Visual Permukiman Bantaran Sungai Studi Kasus: Kampung Code Utara, Yogyakarta. Teknik, Vol. 34 (2).

Rahardjo, T. (2015). Sekolah Biasa Saja: Panduan Untuk Sekolah Dasar. Yogyakarta: Progress.

Reed, J. Saunders, K. \& Simonds, S.P. (2015). Problem-Posing in a Primary Grade Classroom Utilizing Freire's Methods to Break the Culture of Silence. Multicultural Education, vol. 23, No. 1.

Rise.smeru.or.id. (2019). Dampak sistem zonasi penerimaan peserta didik baru di sekolah negeri bagi para guru dan siswa. http://www.rise.smeru.or.id/id/blog/dampak-sistem-zonasipenerimaanpeserta-didik-baru-di-sekolah-negeri-bagi-para-guru-dan-siswa.

Stoker, G. (2006). Explaining Political Disenchantment: Finding Pathways to Democratic Renewal. The Political Quarterly, Vol. 77(2): 184-194.

Tilaar, H.A.R. (2009). Kekuasaan dan Pendidikan: Manajemen Pendidikan Nasional Dalam Pusaran Kekuasaan. Jakarta: Rineke Cipta.

Undang-Undang Republik Indonesia Nomor 20 Tahun 2003 Tentang Sistem Pendidikan Nasional UNESCO, 2003. Part 4. 